\title{
CARACTERIZAÇÃO DA VEGETAÇÃO PIONEIRA DE UMA ÁREA DE EXPLORAÇÃO DE MIMOSA SCABRELLA BENTH. (BRACATINGA), NO MUNICÍPIO DE COLOMBO, PR.
}

\author{
Leocádio Grodzki ${ }^{1}$ \\ Maria Regina Torres Boeger ${ }^{2}$
}

\begin{abstract}
RESUMO
Com o objetivo de melhor entender a dinâmica sucessional dos bracatingais, realizou-se um levantamento florístico e fitossociológico das espécies instaladas após 60 dias do corte raso da bracatinga (Mimosa scabrella Benth.). O local de estudo é uma área no município de Colombo, PR., de sistema agrosilvicultural (bracatinga+milho, feijão e abóbora), circundada por bracatingais de diversas idades, cultivo e pastagens. Foram delimitadas 30 parcelas de $1 \mathrm{~m}^{2}$, para a avaliação florística e fitossociológica, utillizando-se o método de Braun-Blanquet. Avaliou-se a frequiência e cobertura relativas. Foram identificadas 32 espécies sendo 13 herbáceas e 19 arbustivas e/ou arbóreas. As espécies herbáceas mais freqüentes e de maior valor de cobertura foram: Panicum sabulorum, Cyperus hermaphroditus e Imperata brasiliensis, enquanto que entre as arbóreas e/ou arbustivas foram: Leandra australis e Palicourea sp.. Detectou-se, também, a presença de várias rebrotas de espécies arbóreas, mostrando que, mesmo após vários ciclos de exploração agrosilvicultural, ainda ocorre regeneração de muitas espécies da floresta original.
\end{abstract}

Palavras chave: espécies pioneiras, fitossociologia, florística, sistema agrosilvicultural

\section{CHARACTERIZATION OF THE PIONEER VEGETATION ON THE BRACATINGA (Mimosa sScabrella BENTH.) AGROFORESTRY SYSTEM IN THE COLOMBO MUNICIPALITY , PR.}

\begin{abstract}
To better understand the successional dynamics of "bracatinga" forests, a floristical and fitossociological survey was performed after 60 days after the cutting of the bracatinga (Mimosa scabrella Benth.) in an agroforestry system area (bracatinga + corn, beans and pumpkin), in the municipality of Colombo, PR. Thirty plots of $1 \mathrm{~m}^{2}$ were delimited, using the method of BraunBlanket. Frequency and relative covering were defined for each plant species. Thirty-two species (13 herbaceous and 19 tree species) were detected. The herbaceous species with most frequent and larger value of coverage are: Panicum sabulorum, Cyperus hermaphroditus and Imperata brasiliensis. Among the tree species, the one with greater values are: Leandra australis and Palicourea sp. Sprouting was frequent for several tree species, sugesting that, even after several cycles of explotation, regeneration of many species of the original forest still occurs.
\end{abstract}

Key-words: pioneer species, floristics, phytossociology, agroforestry system.

\section{INTRODUÇÃO}

A bracatinga (Mimosa scabrella Benth.) tem sido utilizada como lenha, carvão vegetal e na construção civil, gerando grandes extensões de bracatingais sobre as áreas de florestas nativas. $\mathrm{O}$ sistema tradicional da bracatinga é praticado em propriedades agrícolas e atualmente representa uma área de 60.000 ha somente na Região Metropolitana de Curitiba (LAURENT et al., 1990). Cerca de $75 \%$ das propriedades utilizam o sistema de exploração agrícola em forma de consórcio no primeiro ano da floresta e $90 \%$ não praticam desbaste após o primeiro ano, deixando a floresta em competição natural (BAGGIO et al., 1986). A bracatinga, por ser uma espécie pioneira e de rápido crescimento,

\footnotetext{
${ }^{1}$ M. Sc., Dr. Engenheiro Agrônomo, pesquisador do IAPAR/SIMEPAR

${ }^{2}$ M.Sc., Dr. Bióloga, Professora Adjunta da UFPR.
} 
permite que o corte raso seja efetuado num período de 6 a 8 anos, não havendo tempo hábil para a instalação e manutenção plena de um sub-bosque com maior diversidade.

Após o corte raso, é prática usual a queima dos resíduos da exploração. Isto proporciona a quebra de dormência das sementes acumuladas em diferentes camadas do solo e a consequiente regeneração natural da floresta (CARNEIRO et al., 1982). Posteriormente ao corte raso, ocorre uma proliferação das plantas anuais. Entretanto, o estudo sobre estas espécies tem sido limitado, pois são rapidamente eliminadas pelas atividades de cultivo.

Com a execução desse trabalho, pretende-se caracterizar a vegetação pioneira, que se estabelece após o corte da bracatinga, contribuindo com o conhecimento da dinâmica sucessional natural dessas comunidades, mediante a apresentação dos dados de um levantamento florístico e fitossociológico das espécies presentes após 60 dias do corte raso da bracatinga.

\section{MATERIAL E MÉTODOS}

Local de estudo: O estudo foi realizado em Poço Fundo, no município de Colombo, PR, nas coordenadas geográficas de $25^{\circ} 16^{\prime} 36^{\prime \prime}$ de latitude Sul e $49^{\circ} 04^{\prime} 58^{\prime \prime}$ de longitude Oeste de Greenwich, numa altitude próxima de $900 \mathrm{~m}$. O local de estudo é uma área particular de exploração no sistema agro-silvicultural convencional (bracatinga+milho, feijão e abóbora), de aproximadamente 5 ha, circundada por bracatingais de diversas idades, áreas de cultivo e pastagens, em terreno fortemente ondulado, o qual não permite a mecanização de qualquer atividade. A exploração constitui-se em roçada após o corte e retirada da madeira/lenha realizada entre março e maio, queima controlada da área, realizada entre agosto e setembro, para favorecer o estabelecimento da bracatinga, e semeadura das lavouras com matraca, sacho ou enxada, sem portanto alterar a constituição física do solo.

Pelo histórico da área, a adubação não é normalmente utilizada, sendo que as culturas extraem os nutrientes reciclados da matéria orgânica resultante da bracatinga e de outras espécies vegetais que ocorriam na área.

Na região do estudo, a vegetação original é classificada como Floresta Ombrófila Mista, de acordo como o sistema proposto por IBGE (1990). O solo predominante é um Cambissolo de textura argilosa, com horizonte A moderado (aproximadamente $12 \mathrm{~cm}$ ), cinza escuro pela presença de matéria orgânica, com 1 metro de profundidade na crista do relevo, apresentando teores baixos de $\mathrm{Ca}, \mathrm{Mg}, \mathrm{P}$, K e alta concentração de Al (EMBRAPA, 1988).

$\mathrm{O}$ clima da região é classificado como $\mathrm{Cfb}$ (Köeppen), no qual ocorre em média 10 geadas/ano, a média do mês mais frio é inferior $a 18^{\circ} \mathrm{C}$ e do mês mais quente é superior a $22^{\circ} \mathrm{C}$, não apresentando estação seca definida, com precipitação em torno de $1450 \mathrm{~mm} /$ ano e umidade relativa superior a 80\% (IAPAR,1994). Há variabilidade de direção dos ventos, com predominância da direção NE/E.

Metodologia: Para o levantamento florístico e fitossociológico foram delimitadas, aleatoriamente, 30 parcelas de $1 \mathrm{~m}^{2}$, sendo cada parcela sub-dividida em quadrados menores com 10 $\mathrm{cm}$ de lado. Para cada parcela, foram coletadas as espécies ocorrentes e avaliados o fator de cobertura e a freqüência, utilizando-se o método de escala de cobertura-abundância de Braun-Blanquet (MUELLER-DUMBOIS e ELLEMBERG, 1974), por tratar-se de espécies herbáceas e de espécies arbustivas e arbóreas muito jovens. A freqüência foi determinada estimando-se o número de ocorrências de cada espécie nas 30 parcelas e a cobertura pela área ocupada pela vegetação, em percentagem. A identificação botânica das espécies amostradas baseou-se em chaves analíticas, comparação com material botânico de outros herbários e em consultas à especialistas e à literatura especializada. O material botânico foi utilizado para a elaboração de um herbário de campo, uma vez que a maioria do material herborizado encontrava-se no estádio jovem, portanto, infértil.

\section{RESULTADOS E DISCUSSÃO}

Foram identificadas 32 espécies sendo 13 espécies herbáceas e 19 espécies arbustivas e/ou arbóreas (Tabela 01), distribuídas em 20 famílias (Figura 01). As famílias com maior número de espécies foram as famílias Poaceae e Asteraceae, ambas com representantes herbáceos. 
Tabela 01 . Lista de espécies das parcelas amostradas. Hábito: H = herbáceo; A = arbóreo/arbustivo.

\begin{tabular}{|c|c|c|}
\hline Família & ESPÉCIE & ÁBITO $^{\mathrm{H}}$ \\
\hline Agavaceae & Cordilyne dracaenoides Kunth & A \\
\hline Asteraceae & Baccharis anomala DC. Prodr & $\mathrm{H}$ \\
\hline Asteraceae & Espécie não identificada 01 & $\mathbf{H}$ \\
\hline Asteraceae & Chaptalia nutans Hemsl & $\mathrm{H}$ \\
\hline Asteraceae & Eupatorium sp. & A \\
\hline Blechnaceae & Blechnum cf. occidentale L. & $\mathrm{H}$ \\
\hline Bignoniaceae & Jacaranda puberula Cham. & A \\
\hline Celastraceae & Maytenus cf. evonymoides Reisseck & $A$ \\
\hline Clethraceae & Clethra scabra Loisel & A \\
\hline Cyperaceae & Rhynchospora uleana Boeck. & $\mathrm{H}$ \\
\hline Cyperaceae & Cyperus hermaphroditus (Jack.) Standley & $\mathrm{H}$ \\
\hline Fabaceae & Machaerium stipitatum Vog. & A \\
\hline Lauraceae & Ocotea puberula Nees. & A \\
\hline Melastomataceae & Leandra cf. australis Cogn. & A \\
\hline Mimosaceae & Mimosa scabrella Benth. & A \\
\hline Mimosaceae & Espécie não identificada 02 & $\mathbf{A}$ \\
\hline Myrcinaceae & Myrsine sp. & A \\
\hline Myrtaceae & Myrcia sp. & A \\
\hline Myrtaceae & Campomanesia cf xanthocarpa Berg. & A \\
\hline Pteridaceae & Pteridium aquilinum var.arachnoideum (Klf.) Herter & $\mathrm{H}$ \\
\hline Poaceae & Imperata brasiliensis Trinius. & $\mathrm{H}$ \\
\hline Poaceae & Paspalum notatum Fluegge. & $\mathrm{H}$ \\
\hline Poaceae & Homolepis villaricense (Mez.) Zuloaga et Soderstrom & $\mathrm{H}$ \\
\hline Poaceae & Panicum sabulorum Lam & $\mathrm{H}$ \\
\hline Poaceae & Oplismenus sp. & $\mathrm{H}$ \\
\hline Rubiaceae & Psychotria sp. & A \\
\hline Rubiaceae & Palicourea sp. & A \\
\hline Sapindaceae & Matayba elaeagnoides Radlk. & A \\
\hline Solanaceae & Solanum cf. megalochiton Mart. & $\mathrm{H}$ \\
\hline Symplocaceae & Symplocus sp. & A \\
\hline Rosaceae & Rubus brasiliensis Mart. & A \\
\hline Rosaceae & Rubus cf urticaefolius Poir. & A \\
\hline
\end{tabular}


Figura 01 Relação de famílias e número de espécies

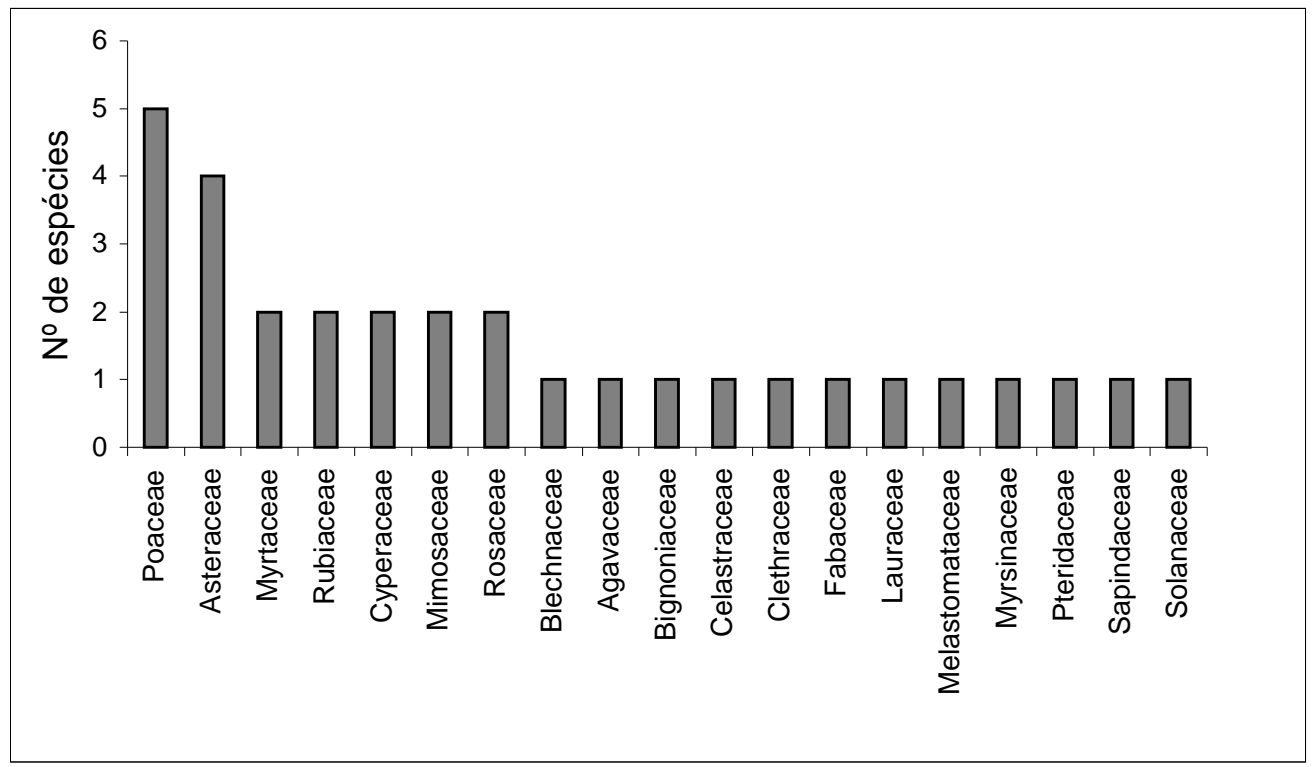

As espécies herbáceas mais frequientes foram: Panicum sabulorum, Cyperus hermaphroditus e Imperata brasiliensis e dentre as arbóreas e/ou arbustivas, além de Mimosa scabrella, foram: Leandra australis, Solanum megalochiton e Palicourea sp.

(Figura 02). As espécies herbáceas com maior grau de cobertura foram Panicum sabulorum, Cyperus hermaphroditus e Paspalum notatum e as espécies arbóreas e/ou arbustivas foram Leandra australis e Palicourea sp. (Figura 03).

Figura 03 - Cobertura relativa das espécies

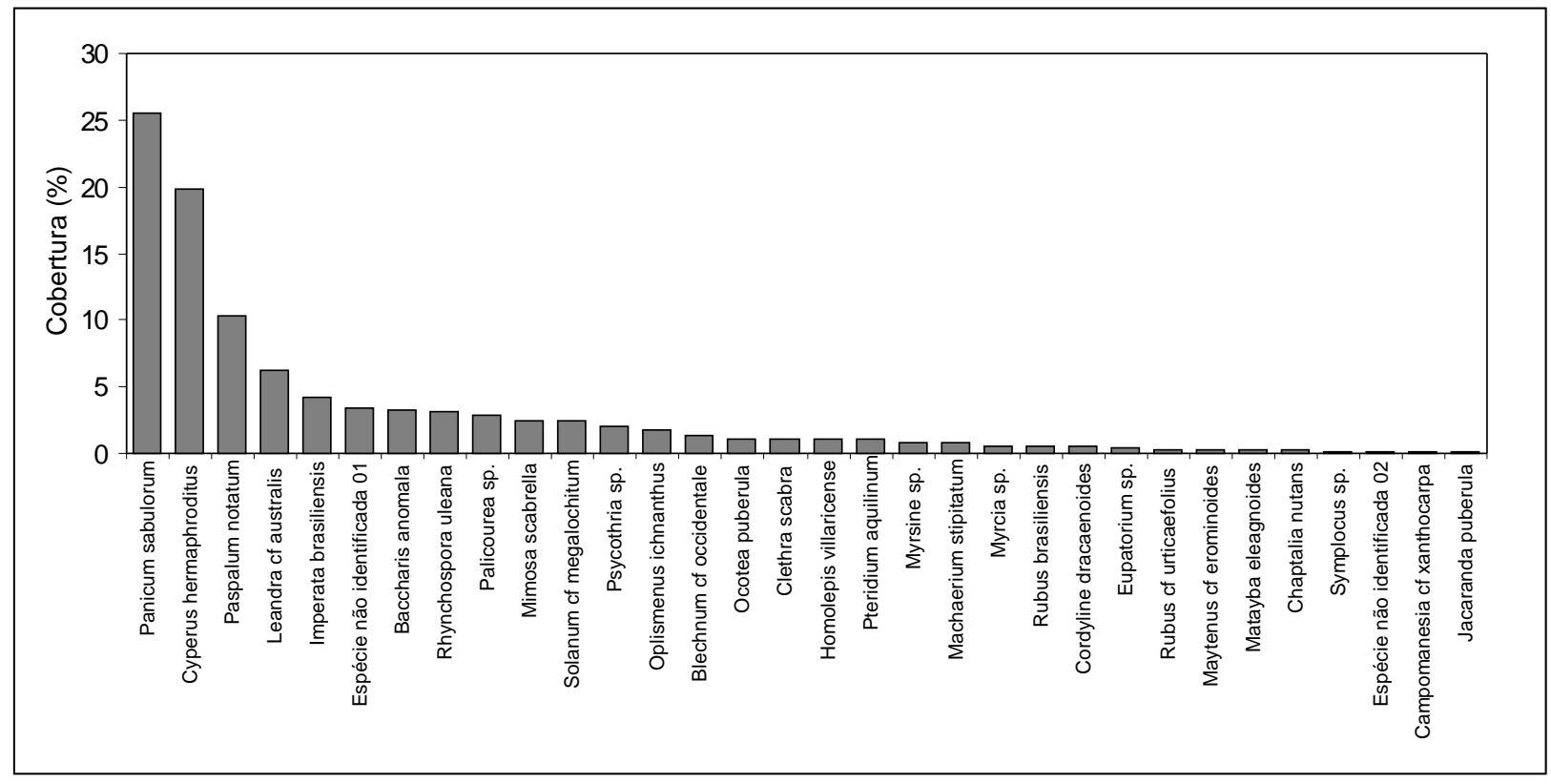

A

ocorrência de diversas espécies herbáceas na área ocorre em função da eficiente dispersão anemocórica de sementes oriundas das áreas circunvizinhas, do banco de sementes do solo, além da 
alta taxa de viabilidade destas sementes, apesar da queima. (KLEIN,1962; BAGGIO el al., 1995). Estas espécies tendem a diminuir em termos de freqüência e cobertura com o passar do tempo, devido

a formação do dossel do bracatingal, que reduz a penetração da radiação solar. O tempo de permanência destas espécies no sistema é pequeno, pois são capinadas já no primeiro ano e tem sombreamento da bracatinga após este período, mas ainda assim permanecem no ecossistema.

Os escassos estudos sobre florística e parâmetros fitossociológicos em bracatingais mostram que este sistema apresenta uma composição florística bastante heterogênea. Comparando-se os dados obtidos neste estudo com os de outros autores, apenas 7 espécies das 35 espécies listadas por CARVALHO (1981) são coincidentes; 4 gêneros e 1 espécie coincidem com a lista de 11 espécies de BAGGIO et al. (1986) e 5 das 21 espécies listadas por BAGGIO et al. (1995). Entretanto, é importante salientar que os estudos anteriormente citados foram realizados em áreas com diferentes idades, evidenciando a dinâmica sucessional deste ecossistema, onde a substituição de espécies é rápida.

Detectou-se também a presença de espécies características de estágios sucessionais mais tardios como a Ocotea puberula, que é uma das espécies dominantes da floresta secundária, onde ocupa cerca de $50 \%$ da cobertura superior (KLEIN, 1962)

Em relação às espécies herbáceas, apenas o levantamento de KLEIN (1962) lista as espécies que ocorrem nos bracatingais, logo após o corte raso. Entre as espécies citadas, apenas 4 foram coincidentes com o estudo aqui apresentado. Dentre estas, Imperata brasiliensis e Pteridium aquilinum são indicadoras de solos mais fracos e esgotados em sucessivos cultivos e queimadas, por serem resistentes devido aos rizomas profundos e coriáceos que apresentam (KLEIN, 1962).

$\mathrm{Na}$ área estudada, além das espécies levantadas nas parcelas, detectou-se a presença de regeneração (a maioria através de rebrotas) de várias espécies arbóreas, evidenciando que, mesmo após vários ciclos de exploração agrosilvicultural (a cada 6-8 anos), ainda ocorre regeneração de muitas espécies da comunidade vegetal original.

Além disso, várias espécies arbóreas tem suas sementes dispersas pelo vento, já que a área em estudo sofre grande pressão das áreas florestadas adjacentes. Este mosaico de pequenas áreas exploradas, entre áreas recobertas com bracatingais ou vegetação natural, favorece o rápido repovoamento.

Entretanto, os estudos de vegetação em sistemas agroflorestais são escassos, para observações mais conclusivas. Os resultados encontrados até agora indicam que existe variação entre a composição florística destes sistemas e só com levantamentos mais detalhados por micro-região é que poderemos ter um conhecimento real da distribuição dessas espécies e conseqüentemente um melhor aproveitamento e manejo dos bracatingais.

\section{BIBLIOGRAFIA CITADA}

BAGGIO, A . J.; CARPANEZZI, A.A.A; GRAÇA, L.R; CECCON, E. Sistema agroflorestal da bracatinga com culturas anuais. Boletim de Pesquisa Florestal, 12: 73-82. 1986

BAGGIO, A.J.; CARPANEZZI, A.A.A.; CARVALHO, P.E.R. \& SOARES, A.O. Levantamento de espécies lenhosas em sub-bosques de bracatingais. Boletim de Pesquisa Florestal, 30/31: 6974.1995.

CARNEIRO, R. M.; ALMEIDA Jr, A . R. de., KAGEYAMA, P.Y.; DIAS, I. de S..

Importância da dormência das sementes na regeneração da bracatinga - Mimosa scabrella, Benth. Piracicaba, IPEF, Circular Técnica 149: 1-10. 1982.

CARVALHO, P.E.R. Composição e crescimento da bracatinga em povoamento natural $I n$ : SEMINÁRIO SOBRE ATUALIDADES E PERSPECTIVAS FLORESTAIS. 4."Bracatinga, uma alternativa para reflorestamento", Curitiba. Anais. EMBRAPA-URPFCS,1981.p.67-75. (EMBRAPA-URPFCS. Documentos,5).1981.

EMBRAPA. Centro Nacional de Pesquisa de Florestas (Colombo, Pr.). Manual Técnico da bracatinga (Mimosa scabrella, Benth.). Colombo, 1988. 70p. (EMBRAPA-CNPF. Documentos, 20).

IBGE. Manual Técnico da Vegetação Brasileira. Rio de Janeiro. 1990. Séries Manuais Técnicos em Geociências, 1)

IAPAR - Cartas climáticas do Estado do Paraná. Instituto Agronômico do Paraná, Londrina. (IAPAR, 
Documentos, 18). 1994.

KLEIN, R.M. Fitofisionomia e notas sobre a vegetação para acompanhar a planta fitogeográfica dos municípios de Rio Branco do Sul, Bocaiuva do Sul, Almirante Tamandaré e Colombo, Paraná. Boletim da Universidade do Paraná 3:1-33. 1962.

LAURENT, J.M.E.; M.R.R. PEDREIRA; O. T. B. CARPANEZZI; S.M. BITTENCOURT. Melhoramento do Sistema Agroflorestal da Bracatinga. FAO-Projeto GCP/BRA/025/FRA. (Série Estudos Florestais 6). 1990.

MUELLER-DUMBOIS, D. e H. ELLEMBERG. Aims and Methods of Vegetation Ecology. John Wiley e Sons. New York. 1974.

Agradecimentos

Os autores agradecem ao Sr. Antonio Andreatta e família, proprietário da área, aos Drs. Sandro Menezes Silva, Carlos V. Roderjan e Clélia P. Pereira pela identificação do material botânico. 